\title{
Dengue: uma nova abordagem
}

\author{
Dengue: a reappraisal
}

\author{
José Carlos Serufo', Vandack Nobre', Abdunnabi Rayes'1, \\ Tânia Maria Marcial ${ }^{2}$ e José Roberto Lambertucci ${ }^{1}$
}

\begin{abstract}
Resumo Os conceitos de dengue clássico, com ou sem hemorragia, e de febre hemorrágica do dengue (FHD) que, pode cursar sem fenômenos hemorrágicos, com ou sem síndrome do choque do dengue (SCD), são revistos neste artigo. As definições clássicas propostas, úteis em outros tempos, geram confusão e dificultam a tomada de decisões no momento do tratamento dos pacientes com as formas graves da doença porque deixaram de incorporar novos conceitos e avanços terapêuticos. A classificação do dengue proposta neste trabalho, e apresentada em fluxograma, incorpora os conceitos atuais de sepse, síndrome da resposta inflamatória sistêmica (SIRS) e síndrome da angústia respiratória do adulto (SARA). A nova classificação serve de guia para orientar a conduta terapêutica inicial e aproxima o tratamento do dengue aos protocolos $e$ rotinas já implantados nos diversos centros hospitalares de urgência, facilitando a atuação dos serviços de saúde em situações de surtos epidêmicos.
\end{abstract}

Palavras-chaves: Dengue. Febre hemorrágica do dengue. Sepse. Síndrome da angústia respiratória do adulto (SARA). Síndrome da resposta inflamatória sistêmica (SIRS).

\begin{abstract}
Previous definition of classic dengue, with or without bleeding, and of dengue hemorrhagic fever (DHF) that may evolve without bleeding and with or without dengue shock syndrome (DSS) are reviewed here. The classical approach to the diagnosis and treatment of dengue, although useful in the past, nowadays breeds confusion and adds a burden to the physician's task of decision-making regarding the treatment of patients with severe forms of the disease. The classification of dengue proposed in this paper, and summarized in a diagram, incorporates new concepts about sepsis, systemic inflammatory response syndrome (SIRS), and acute respiratory distress syndrome (ARDS). This new approach, in our view, is a useful guide to initial evaluation and treatment of the disease. It also approximates the dengue syndrome to other protocols and medical procedures routinely used in intensive care units, making it easier to be followed by the health personnel working in areas subject to epidemic bursts.
\end{abstract}

Key-words: Dengue. Dengue hemorrhagic fever. Sepsis. Acute respiratory distress syndrome (ARDS). Systemic inflammatory response syndrome (SIRS).

A observação de que a síndrome séptica se desenvolve à base de uma resposta inflamatória do organismo acometido não constitui novidade, mas foi a partir da publicação do Consenso da
American College of Chest Physicians/Society of Critical Care Medicine (ACCP/SCCM) - Sepse e Falência Orgânica ${ }^{1}$, em 1992, que esse conceito se solidificou entre clínicos e intensivistas (Tabela 1).

\footnotetext{
1. Departamento de Clínica Médica da Faculdade de Medicina da Universidade Federal de Minas Gerais. Serviço Doenças Infecciosas e Parasitárias. 2. Infectologista do Hospital Eduardo de Menezes. Consultora de Febres Hemorrágicas da Sociedade Mineira de Infectologia.

Endereço para correspondência: Dr. José Carlos Serufo. Departamento de Clínica Médica. Av. Alfredo Balena 190, 30130-100 Belo Horizonte, MG, Brasil.

Fax: 55312212708 .

e-mail: serufo@brhs.com.br

Recebido em 29/3/2000
} 
A incorporação do termo SIRS (do inglês, systemic inflammatory response syndrome), ainda que sob críticas de importantes pesquisadores ${ }^{33}$, ocorreu de forma contundente, facilitando o entendimento da fisiopatologia do processo e a percepção de inúmeras situações ditas sepse-símile. Essas se constituem em SIRS sem infecção associada, exemplificando-se o trauma, a pancreatite aguda e o choque hemorrágico grave.
A importância maior de se reconhecer a síndrome da resposta inflamatória sistêmica está na possibilidade de atuarmos precocemente sobre ela, impedindo que o processo se estenda e evolua para formas mais graves como choque e conseqüente falência de órgãos (Figura 1).

Sabe-se que diversos microrganismos podem desencadear a sepse, sendo o padrão de resposta inflamatória bastante homogêneo,

Tabela 1 - Definições de síndrome da resposta inflamatória sistêmica (SIRS), sepse, choque e síndrome da disfunção orgânica múltiplá.

1-SIRS *(Síndrome da Resposta Inflamatória Sistêmica): Definida pela presença de dois ou mais dos seguintes achados: (1) temperatura corporal maior que $38^{\circ} \mathrm{C}$ ou menor que $36^{\circ} \mathrm{C}$; (2) taquicardia com freqüência cardíaca maior que $90 \mathrm{bpm}$; (3) taquipnéia ou freqüência respiratória maior que 20 irpm, ou hiperventilação, indicada por $\mathrm{PaCO} 2$ menor que $32 \mathrm{mmHg}$; e (4) alteração na contagem leucocitária, ou seja, um número maior que 12.000 células ou menor que 4.000 por $\mathrm{mm}^{3}$. A presença de formas jovens representando mais que $10 \%$ dos neutrófilos também deve ser incluída no critério.

2-Sepse: quando a SIRS é relacionada a processo infeccioso confirmado.

3-Sepse grave: definida como processo associado à disfunção orgânica, hipoperfusão ou hipotensão. A anormalidade da perfusão é definida por oligúria, alteração do estado mental ou acidose láctica.

4-Hipotensão associada a sepse: definida como pressão arterial sistêmica menor que $90 \mathrm{mmHg}$ ou uma redução de mais que $40 \mathrm{mmHg}$ na pressão arterial de base.

5-Choque séptico: quando persiste hipotensão, a despeito de adequada reposição volêmica, juntamente com a presença de disfunção orgânica e sinais de hipoperfusão.

6-Síndrome da Disfunção Orgânica Múltipla (MODS): alteração da função orgânica em paciente agudamente enfermo, definida pela impossibilidade de se manter a homeostase sem intervenção médica.

*pode ser causada por infecções e por uma grande variedade de condições não infecciosas, como pancreatite, choque hemorrágico, isquemia, politrauma acidental ou trauma cirúrgico e administração de mediadores da inflamação como fator de necrose tumoral (FNT) e citocinas.

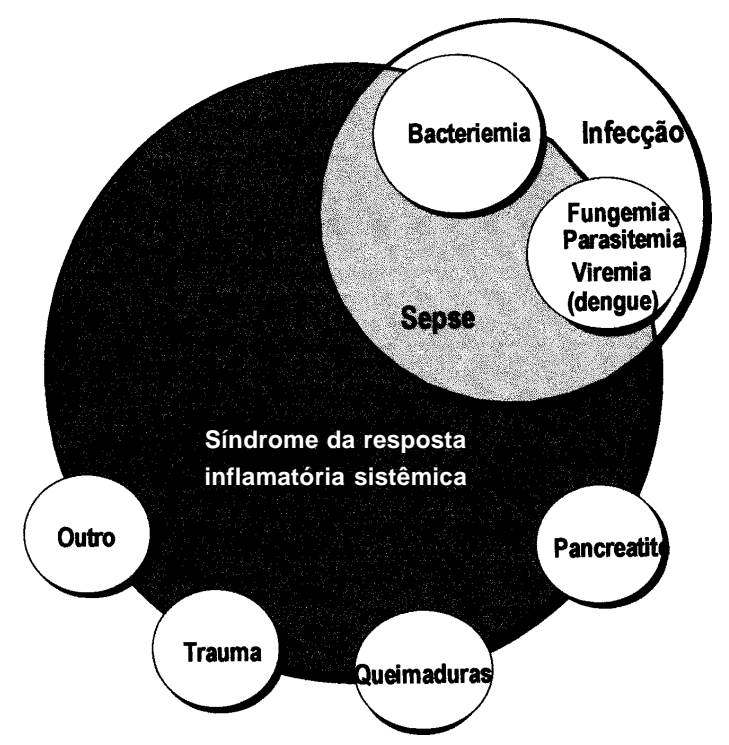

Figura 1 - Interrelação entre infecção, sepse e síndrome da resposta inflamatória sistêmica. 
independentemente da etiologia, seja ela bacteriana, fúngica ou viral ${ }^{36}$. A febre hemorrágica do dengue (FHD) e a síndrome do choque do dengue (SCD) se constituem em formas claras de sepse por vírus devendo, portanto, ser abordadas como tal. São inegáveis, no entanto, algumas peculiaridades existentes na fisiopatologia dessa infecção, notadamente aquelas relacionadas ao aumento significativo e precoce da permeabilidade vascular, assim como as decorrentes de distúrbios da coagulação sanguínea ${ }^{37}$.

Nosso objetivo é o de propor uma nova classificação do dengue que incorpore os conceitos de SIRS e sepse facilitando, assim, ao utilizar protocolos de tratamento já implantados, a atuação dos serviços de saúde, em especial dos centros de tratamento intensivo (CTIs), em casos de surtos epidêmicos da doença (Tabela 1).

Considerações fisiopatológicas da sepse. No modelo causado por Gram negativos, etiologia mais comum, a endotoxina, ou seu principal componente o lipopolissacáride A (LPS-A), se liga a diversas moléculas, em especial a proteína ligadora do lipopolissacáride (LBP). Esse complexo (LPS-LBP) então se liga a receptores CD14 dos monócitos e a células que não expressam este receptor (i.e. células endoteliais) através de moléculas de CD14 solúveis.

A ativação do complemento ocorre na maioria dos pacientes. As citocinas, incluindo o FNT (Fator de Necrose Tumoral), IL-1 (Interleucina 1), IL-6 e IL-8, parecem participar tanto do desencadeamento, como da manutenção das respostas inflamatórias no choque séptico, seja individualmente ou em combinação.

Os níveis de FNT encontram-se elevados na maior parte dos casos. Receptores solúveis para o FNT (FTNr) foram detectados na circulação de pacientes sépticos e parece que os seus níveis se correlacionam com a letalidade da doença. A IL-1 também tem sido detectada na circulação de alguns doentes com sepse. Alguns estudos sugerem que a IL-1 e o FNT agem de forma predominantemente sinérgica. Das citocinas estudadas, a IL-6 é aquela que de forma mais convincente se correlaciona com a letalidade. $O$ FNT, IL-1 e IL-6 podem estimular a produção de IL-8, um potente agente quimiotáxico para neutrófilos ${ }^{10} 20$.

Muitos dos efeitos induzidos pelo FNT e IL-1 parecem ser mediados por metabólitos do ácido araquidônico, entre eles a prostaglandina E2 (PGE2) e o tromboxane-A2 (TX-A2). Os leucotrienos, sobretudo o B4 (LT-B4), também parecem participar da resposta inflamatória. $A$ produção de óxido nítrico (ON) constitui evento aceito atualmente como muito importante na patogênese do choque séptico. Em modelos de choque séptico experimental, as quedas da pressão arterial e da resistência vascular sistêmica parecem decorrer da produção dessa substância ${ }^{10}$. A produção de ON é estimulada pelo $\mathrm{FNT}, \mathrm{IL}-1$ e interferon-gama, os quais promovem a formação de óxido nítrico a partir de L-arginina, com a participação do óxido nítricosintetase. Os produtos derivados do ácido araquidônico e o fator ativador de plaquetas (PAF) também parecem participar da indução de hipotensão arterial. As chamadas moléculas de adesão (E-selectina e ICAM-1A) contribuem para a instalação do choque séptico e para a leucopenia e trombocitopenia freqüentemente presentes nesses pacientes. Muitos tipos de células, incluindo neutrófilos, macrófagos, plaquetas e células endoteliais, participam na modulação da cascata inflamatória ${ }^{19} 27$.

Para contrabalançar a cascata pró-inflamatória, o organismo produz algumas substâncias ditas contra-inflamatórias, procurando com isto restabelecer o equilíbrio, evitando assim a ocorrência de grave distúrbio da homeostase. Dentre essas se destacam a IL-4, IL-10, IL-13, inibidor do receptor de IL-1, epinefrina e outros ${ }^{4}$.

No início, a sepse encontra-se freqüentemente acompanhada de hipovolemia, em decorrência da vasodilatação arterial e venosa e da perda de fluido para o interstício, secundária ao aumento da permeabilidade capilar (capillary leak) ${ }^{19}$. No coração ocorrem diminuições das frações de ejeção e aumento dos volumes diastólicos finais de ambos os ventrículos, enquanto o volume sistólico permanece normal. O aumento observado no índice cardíaco se deve principalmente ao aumento da freqüência cardíaca. Dentre os prováveis mecanismos para explicar a depressão miocárdica na sepse estariam a diminuição do fluxo sanguíneo coronariano ou mais provavelmente a ação direta ou indireta de uma ou mais substâncias circulantes ${ }^{18}$. Demonstrou-se em crianças na Tailândia, através de estudo ecográfico, que no dengue pode ocorrer depressão cardíaca significativa ${ }^{15}$.

$\mathrm{Na}$ sepse, muitos leitos vasculares encontram-se dilatados e outros constritos, o que leva a uma característica distribuição irregular do fluxo sanguíneo. A agregação de plaquetas e 
neutrófilos também contribui através de obstrução vascular. As alterações na macro e microcirculação se associam a distúrbios da oxigenação tissular e da utilização dos nutrientes pelas células, caso eles cheguem até elas. O aumento dos níveis séricos de lactato, acidose metabólica, diminuição na fração de extração de oxigênio e diminuição do consumo de oxigênio pelos tecidos (VO2), numa relação patológica de dependência com o seu transporte (DO2), reforçam essas idéias. Os tecidos, então, não conseguem aumentar a extração de oxigênio, mecanismo através do qual normalmente ocorre a compensação ${ }^{19}$.

A mensuração do $\mathrm{pH}$ intramucosa gástrica (pHi) é outro método de avaliação da oxigenação tecidual refletindo diretamente o que ocorre no estômago, sendo os resultados estendidos ao restante do trato gastrintestinal. A redução significativa do $\mathrm{pHi}$ se correlaciona com pior prognóstico. Embora se constitua em método útil, de baixo custo e simples, não tem sido empregado na rotina dos nossos CTIs (Figura 2).

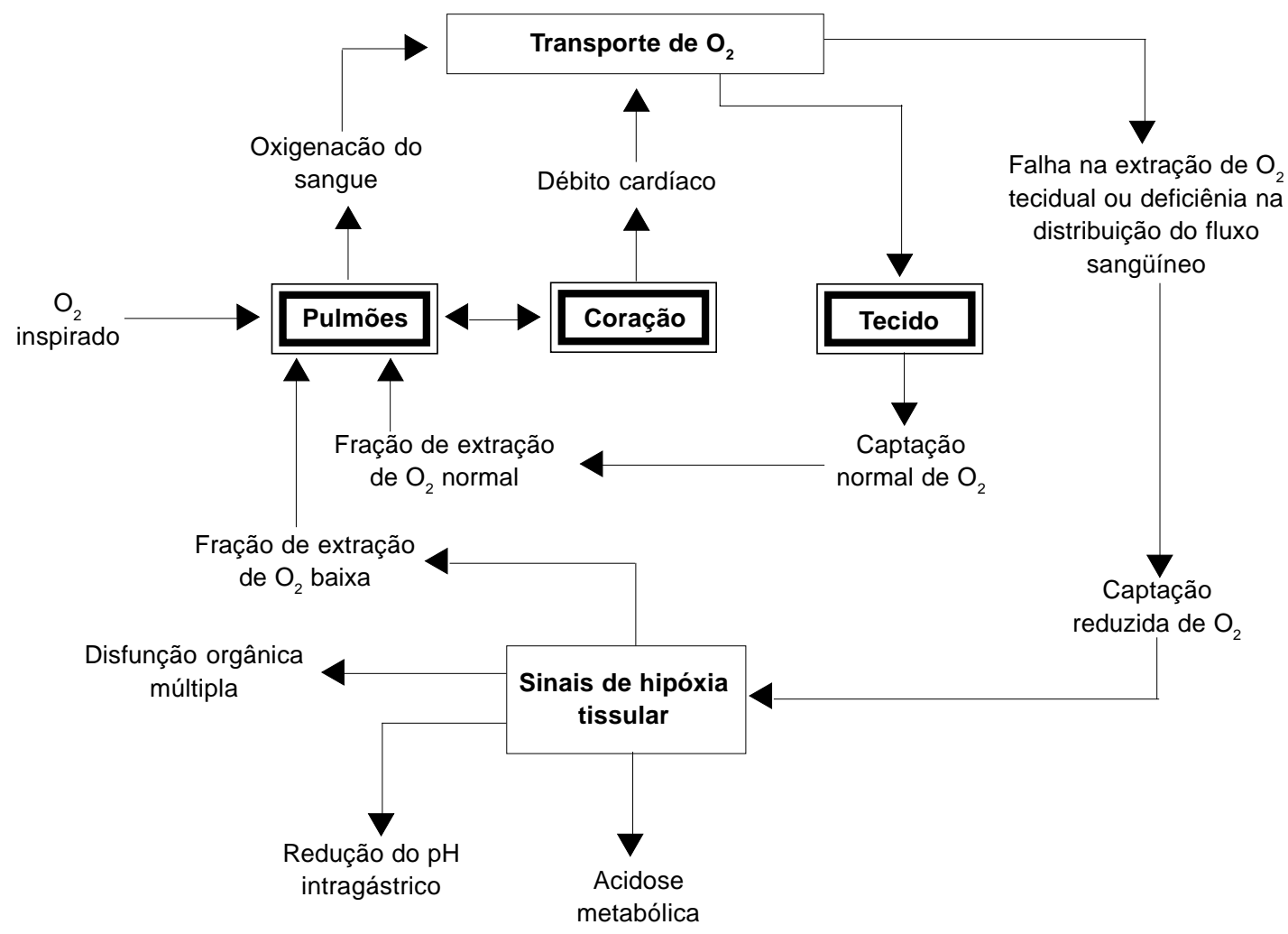

Figura 2 - Fisiopatogenia da sepse.

Há fenômenos inflamatórios resultantes da leucostase e da desgranulação neutrofílica, levando a dano induzido por enzimas e radicais livres de oxigênio. Pensa-se que o óxido nítrico, produzido pelas células musculares lisas, contribui diretamente para a hipotensão e vasoplegia refratárias que podem instalar-se no decorrer da sepse. Seus níveis têm sido correlacionados com uma maior incidência de disfunção renal ${ }^{12} 26$. A
Síndrome da Angústia Respiratória do Adulto (SARA) freqüentemente ocorre como resultado de todos esses processos, atingindo, em média, $25 \%$ dos pacientes ${ }^{3}$. Também no dengue esse problema parece relevante ${ }^{29}$. Oligúria, como resultado da necrose tubular aguda, dano hepático e necrose isquêmica intestinal revelam-se comuns no choque séptico. Cerca de $50 \%$ dos casos de insuficiência renal aguda devem-se a 
sepse $^{26}$. Alguns estudos registram aumento na permeabilidade intestinal, levando ao fenômeno de translocação bacteriana, com muitas das respostas inflamatórias observadas na sepse e na falência de múltiplos órgãos ${ }^{14}$.

Distúrbios da coagulação e na fibrinólise mostram-se comuns nos doentes sépticos. $O$ distúrbio mais significativo é a coagulação intravascular disseminada (CIVD) ${ }^{16}$, um processo caracterizado por trombose microvascular, consumo de plaquetas e proteínas da coagulação, além da estimulação do sistema fibrinolítico. Em choque séptico, sua incidência pode ser de até $70 \%{ }^{16} 29$.

Sinais e sintomas do dengue. Forma assintomática: nesta forma da doença os sintomas não são perceptíveis ao paciente. Estima-se que em uma epidemia de dengue ocorra um caso assintomático para cada cinco casos sintomáticos.

Forma indiferenciada: assemelha-se à síndrome gripal. O paciente apresenta sintomatologia leve, confundindo seu quadro clínico com gripe e muitas vezes não procura atendimento médico. Quando o faz, o diagnóstico clínico inicial é de gripe.

Formas atípicas: o dengue pode manifestarse com formas clínicas atípicas, simulando outras doenças. Na hepatite pelo vírus do dengue ocorre elevação importante das transaminases e presença de icterícia. A doença pode apresentarse com febre, dor abdominal e vômitos, quadro indistinguível das outras hepatites virais agudas.

Podem ocorrer formas raras com comprometimento do sistema nervoso central manifestando-se com encefalites (Síndrome de Reye) ou polineuropatias (Síndrome de GuillainBarré). Essas formas podem surgir no decorrer da doença ou na fase de convalescença.

Dengue clássico: o quadro inicia-se subitamente com febre alta, acompanhada de cefaléia intensa, que pode ser retro-orbital e/ou holocraniana. Acompanham o quadro mialgia intensa e generalizada e, algumas vezes, artralgias. O exantema do dengue surge por volta do terceiro ou quarto dia da doença, sendo mais comum nas extremidades, podendo apresentar-se em todo o corpo. Mostra-se característico da doença o prurido intenso na fase de remissão do exantema. A dor abdominal no hipocôndrio direito, raramente acompanhada de hepatomegalia, ocorre em pequena parcela dos casos. Náuseas e vômitos também podem surgir no início do quadro e algumas vezes o paciente apresenta diarréia. Linfoadenomegalia e esplenomegalia são raras. $\mathrm{Na}$ fase de convalescença o paciente pode apresentar astenia e depressão por um período de um a dois meses. Há relatos também de distúrbios psiquiátricos.

No dengue clássico segundo os tratados e manuais podem ocorrer fenômenos hemorrágicos que geralmente são leves, do tipo epistaxe e gengivorragia, mas que podem apresentar-se tão intensos a ponto de levar ao choque hipovolêmico ${ }^{37}$. Segundo esse critério, em uso atualmente, essa não seria a febre hemorrágica do dengue. Em nossa opinião, do ponto de vista terapêutico essa apresentação da doença deve ter uma abordagem voltada para o controle da hemorragia, reposição volêmica com cristalóides e/ou sangue e hemoderivados, tal como ocorre com outras doenças hemorrágicas, justificando-se sua classificação à parte.

Febre hemorrágica do dengue (FHD)/ Síndrome do choque do dengue (SCD): 0 quadro inicia-se de forma semelhante ao dengue clássico, com febre (ocasionalmente 40 a $41^{\circ} \mathrm{C}$ ), mantendo-se elevada por período de 2 a 7 dias, quando então apresenta queda súbita. Tem sido definida nas situações em que há febre com ou sem manifestações hemorrágicas associadas a trombocitopenia $\left(<100.000 / \mathrm{mm}^{3}\right)$ e presença de um ou mais dos seguintes dados clínicos que caracterizam o extravasamento plasmático: derrame pleural, ascite, elevação do hematócrito em mais de $20 \%$ acima dos valores basais e/ou choque, geralmente acompanhado de valores elevados do hematócrito ${ }^{23} 36$. Os fenômenos hemorrágicos iniciam-se em até 24 horas (prova do torniquete positiva, presença de petéquias, equimoses, epistaxe, gengivorragia, metrorragia, hemorragia digestiva alta). A hepatomegalia surge no início do quadro febril, enquanto a esplenomegalia raramente ocorre, sendo mais comum nos lactentes. A trombocitopenia $\left(<100.000 / \mathrm{mm}^{3}\right)$ ocorre em 70 a $80 \%$ dos casos. Deve-se ressaltar que um período febril maior que 7 dias praticamente descarta o diagnóstico de dengue.

A FHD pode ou não se associar à síndrome do choque do dengue. O choque nessa situação é consequente ao grande aumento da permeabilidade vascular com extravasamento de plasma. Em alguns casos a SCD ocorre antes ou mesmo sem a instalação dos fenômenos hemorrágicos. Consideram-se como sinais e sintomas 
preditores de SCD a dor abdominal contínua, vômitos persistentes, hepatomegalia dolorosa, presença de derrames cavitários, sangramentos importantes, elevação súbita do hematócrito (> 20\% no período de 24 horas). A insuficiência circulatória manifesta-se pela presença de agitação ou letargia, pulso rápido e fraco, taquicardia, hipotensão postural, hipotensão (queda da pressão de pulso > 20mmHg), pele fria e pegajosa, sudorese profusa, cianose, oligúria e choque grave. Podem instalar-se acidose metabólica e coagulação intravascular disseminada. Se o tratamento não for iniciado prontamente o óbito ocorre em 4 a 6 horas. Quando o choque é superado, a recuperação do paciente ocorre em 2 a 3 dias ${ }^{23} 3037$.

Não parece aceitável o termo febre hemorrágica em uma situação em que a hemorragia pode não estar presente e em que os fatores mais importantes na fisiopatogenia são o extravasamento de plasma e o aumento do hematócrito.

Classificação do dengue direcionada à terapêutica. Os conceitos atuais do dengue clássico e febre hemorrágica do dengue apresentam várias contradições. No primeiro caso, considerase a possibilidade de ocorrerem hemorragias e às vezes choque hipovolêmico, podendo levar ao óbito, sem que essas formas sejam definidas como febre hemorrágica do dengue. Por outro lado, pacientes em que a hemorragia inexiste ou não constitui o fator fisiopatológico predominante, mas nos quais há intenso extravasamento de plasma e hemoconcentração se classificam como febre hemorrágica do dengue enquanto a sepse e a SIRS se constituem nos principais componentes fisiopatológicos. Essas distorções deixam a impressão de que o dengue é uma doença infecciosa que se manifesta com um quadro patognomônico e que exige tratamento diferenciado do utilizado nas rotinas dos hospitais e CTIs. Tudo isso provoca grande confusão na abordagem terapêutica desses pacientes. De um modo geral, a maior parte dos serviços de urgência já está habituada a lidar com situações de hemorragias, sepse e resposta inflamatória sistêmica, que podem ocorrer em qualquer doença infecciosa e que são indistinguíveis das apresentadas pelos doentes com dengue.

Definir melhor essas situações aproximando o quadro clínico do dengue de sua terapêutica, considerando o conhecimento atual de sepse e de SIRS e as rotinas já implantadas nos serviços médicos é o objetivo principal da classificação apresentada no fluxograma abaixo (Figura 3 ).

Terapêutica. A princípio, todos os casos classificados como de FHD e sobretudo de SCD, ou de acordo com a classificação proposta por nós, dengue com hemorragias ou com sepse, deveriam ser conduzidos em unidade de terapia intensiva (CTI) ou, ao menos, em unidade intermediária.

A monitorização hemodinâmica mostrou-se útil no diagnóstico e pode tornar-se essencial no tratamento de pacientes mais graves. A pressão venosa central, apesar de sujeita a muitas interferências, constitui uma opção quando se dispõem de poucos recursos e nos pacientes mais jovens, os quais habitualmente possuem boa reserva cardíaca. A utilização do cateter de artéria pulmonar (Swan-Ganz) pode ser benéfica nos pacientes mais instáveis. Esse cateter tem hoje seu uso difundido e representa importante auxiliar para orientar a terapêutica mais adequada a cada paciente. O cateter de Swan-Ganz permite a otimização da reposição volêmica, o ajuste das doses de drogas vasoativas, além da monitorização do débito e do trabalho cardíacos. Adicionalmente, com os dados fornecidos, pode-se calcular o DO2 (transporte de $\mathrm{O} 2$ aos tecidos), VO2 (consumo tecidual de O2), extração de oxigênio (VO2/DO2) e outros dados relevantes. Sua maior indicação encontra-se nos casos em que não se observa melhora com a reposição volêmica e a sua permanência deve ser a mais curta possível, não devendo ultrapassar 3-5 dias ${ }^{22}$. As alterações típicas demonstradas por esse cateter no paciente séptico encontram-se alinhadas na Tabela 2.

Tabela 2 - Parâmetros hemodinâmicos que podem ser obtidos utilizando-se o cateter de artéria pulmonar nos pacientes com choque séptico.

\begin{tabular}{lccccccc}
\hline & \multicolumn{7}{c}{ Parâmetros hemodinâmicos } \\
\cline { 2 - 8 } Choque & PVC & PVD & PAP & PWAP & IC & IRVS & IRVP \\
\hline Precoce & $0-2$ & $20-25 / 0-2$ & $20-25 / 0-6$ & $0-6$ & $\cdot 2,5$ & $<1500$ & $<250$ \\
Tardio* $^{*}$ & $0-4$ & $25 / 4-10$ & $25 / 4-10$ & $4-10$ & $<2,0$ & $>1500$ & $>250$ \\
\hline PVC
\end{tabular}

PVC = pressão venosa central $(n=0-8) ; P V D=$ pressão do ventrículo direito $(n=15-25 / 0-8) ; P A P=$ pressão de artéria pulmonar $(n=15-$ 20/6-12); PWAP = pressão capilar pulmonar $(n=4-12) ; I C=$ índice cardíaco $(n=2,5-4)$; IRVS = índice de resistência vascular sistêmica $(n=1970 / 2390) ;$ IRVP = índice de resistência vascular pulmonar $(n=225-315)$.

*Padrão visto em aproximadamente $1 / 3$ dos pacientes na fase tardia. 


\section{Manifestações clínicas do dengue}

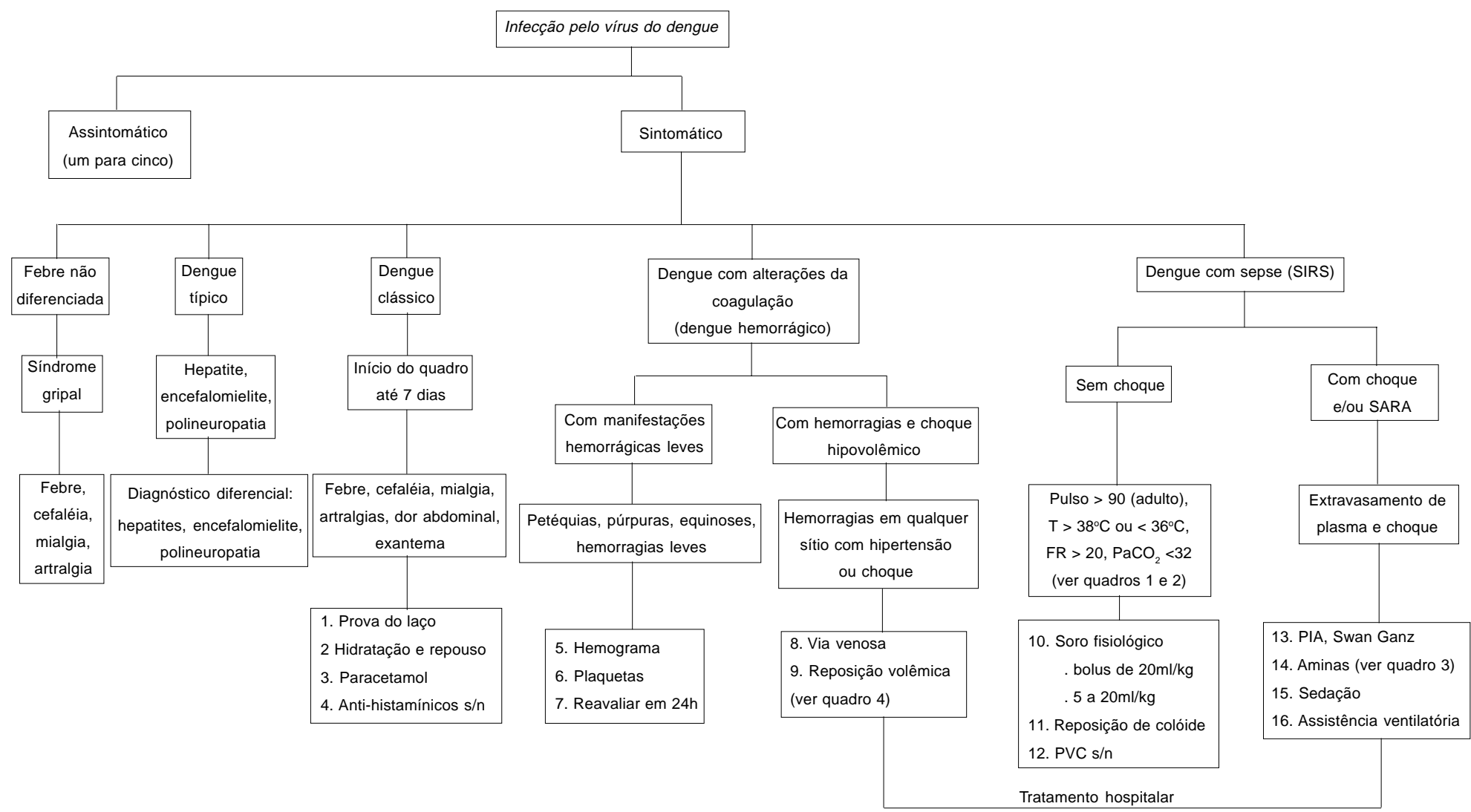

SIRS = Síndrome da resposta inflamatória sistêmica

$P V C=$ Pressão venosa centra

$\mathrm{PIA}=$ Pressão intra-arterial

SARA = Síndrome da Angústia Respiratória do adulto

$\mathrm{s} / \mathrm{n}=$ se necessário 
A monitorização da pressão intra-arterial impõe-se nos casos de choque, devido aos grandes erros que ocorrem quando a pressão arterial é medida com manguito em pacientes hemodinamicamente instáveis. Além disso, permite a coleta freqüente de sangue arterial para gasometria e outros exames que se fizerem necessários. A mensuração do $\mathrm{pH}$ intramucosa gástrica $(\mathrm{pHi})$ é outro método de avaliação da oxigenação tecidual e reflete diretamente o que ocorre no território esplâncnico. A redução significativa do $\mathrm{pHi}$ se correlaciona com hipoperfusão tecidual, representando um marcador precoce de pior prognóstico ${ }^{1122}$.

Outras formas de monitorização podem ser utilizadas de acordo com a disponibilidade e indicação, sendo opções a oximetria de pulso, a dosagem de lactato sérico e menos comumente a calorimetria indireta ${ }^{22}$. A oximetria de pulso, procedimento não invasivo, mostra-se bastante útil na monitorização da assistência respiratória e no acompanhamento de pacientes em risco de desenvolver insuficiência respiratória.

Parece inegável que quanto menos invasivo for o tratamento menores serão as complicações dele decorrentes. No entanto, em pacientes mais graves os benefícios potenciais de uma conduta terapêutica mais agressiva podem suplantar em muito os riscos. Ademais, uma vez que habitualmente a duração do quadro de choque no dengue revela-se curta (2-3 dias), a permanência dos dispositivos de monitorização invasiva também o será, reduzindo a possibilidade de complicações infecciosas, as mais freqüentes e temidas.

Outro aspecto a ser considerado envolve a observação de que no dengue há maior tendência a sangramentos, o que implica maior cuidado na obtenção de acessos vasculares. A escolha do sítio de punção deve se direcionar àqueles mais facilmente compressíveis (i.e. veia jugular interna), e o procedimento sempre realizado por profissionais experientes. No paciente com grave distúrbio da coagulação sanguínea, a dissecção venosa na altura do braço representa a opção mais segura.

Os guias terapêuticos da OMS enfatizam a reposição volêmica como prioridade no tratamento dos pacientes com febre hemorrágica do dengue (FHD) e síndrome de choque do dengue (SCD), iniciando com reidratação oral para o paciente ambulatorial e, de acordo com a gravidade, recomendam esquemas de hidratação venosa mais vigorosa. Assim, naquele paciente que se apresenta com perda de fluido estimada em $5 \%$ ou mais do peso corporal indica-se a administração intravenosa de fluidos com um bolus de solução glicofisiológica (1:1 a 1:2) de $10-20 \mathrm{ml} / \mathrm{kg}$, mantendo-se infusão contínua numa velocidade inicial de $6-7 \mathrm{ml} / \mathrm{kg} /$ hora. Caso ocorra melhora, demonstrada através de queda do hematócrito e da freqüência cardíaca, da estabilização da pressão sangüínea e manutenção de diurese satisfatória, pode-se ir progressivamente reduzindo a velocidade da infusão venosa ao mesmo tempo em que se retorna a hidratação oral. No caso de não haver melhora inicial deve-se aumentar a velocidade da reposição volêmica para algo em torno de $10 \mathrm{ml} / \mathrm{kg} / \mathrm{h}$ atingindo-se até $15 \mathrm{ml} / \mathrm{kg} / \mathrm{h}$ nos casos refratários. A partir daí, se não houver melhora, indica-se a implantação de acesso venoso central para monitorização da PVC e a colocação de sonda vesical de demora para controle da diurese. E após essa fase, não havendo estabilização clínica e laboratorial, avalia-se a necessidade de drogas vasoativas e de sangue total $(10 \mathrm{ml} / \mathrm{kg})$ para queda importante no hematócrito ou alternativamente plasma, albumina ou colóides artificiais $(10-20 \mathrm{ml} / \mathrm{kg})$ no caso de elevação do hematócrito ${ }^{36}$.

O fluxograma que apresentamos indica no paciente com sepse, sem choque circulatório, a reposição volêmica com soro fisiológico, administrando-se um bolus de $20 \mathrm{ml} / \mathrm{kg}$ de peso seguido de infusão contínua de $5-20 \mathrm{ml} / \mathrm{kg} / \mathrm{h}$, de acordo com os parâmetros hemodinâmicos e a resposta clínica. A reposição calórica e de eletrólitos, processar-se-á em solução à parte.

A vantagem de se administrar colóides permanece discutível. Duas meta-análises recentes não mostraram diferenças significativas em relação às duas soluções no que se refere à mortalidade dos pacientes com choque circulatório, incluindo o séptico. No trauma, o cristalóide mostrouse superior ${ }^{25}$. Em especial, quando utilizados em doses acima de $20 \mathrm{ml} / \mathrm{kg} / \mathrm{dia}$, os colóides sintéticos podem trazer problemas relacionados à piora da hemostasia sanguínea, já tão alterada no dengue ${ }^{17}$. Adicionalmente, os colóides têm custo em geral muito superior aos cristalóides, limitando ainda mais a sua indicação ${ }^{31}$. O uso da albumina humana e do plasma expansor têm sido questionados em alguns relatos, os quais chegam a sugerir um aumento da mortalidade com o uso desses agentes ${ }^{8}$. No caso do dengue, considerando ser o aumento da permeabilidade 
capilar uma ocorrência precoce na fisiopatologia da doença, a utilização mais liberal de colóides poderia ser justificada, ainda que não existam estudos que comprovem essa afirmação. Para fins práticos, uma relação de cristalóide para colóide de 1:5 parece razoável. Assim após infundirmos $1000 \mathrm{ml}$ de soro fisiológico, administraríamos $200 \mathrm{ml}$ de colóide a $5 \%$ ou $6 \%$. Dentre os colóides disponíveis pode-se citar a albumina humana e os chamados sintéticos como o hidrometil-amido a $6 \%$ e as gelatinas. A possibilidade de distúrbios hidroeletrolíticos e ácidos básicos deve ser sempre considerada e a correção feita prontamente nos casos em que se fizer necessária.

Dados como débito urinário, características da perfusão periférica do paciente e notadamente no dengue, o hematócrito, devem sempre ser utilizados para adequar a reposição volêmica. A elevação do hematócrito para valores acima de $20 \%$ do valor basal contribui para diferenciar a sepse do dengue da sepse bacteriana clássica.

A avaliação clínica e laboratorial pode ser então complementada pela monitorização hemodinâmica invasiva nos casos mais graves. Ao nosso ver, a indicação desta monitorização hemodinâmica se faz em fases mais precoces do que aquela indicada pelos manuais da OMS. Obviamente, no contexto de uma epidemia, a carência de recursos e de infra-estrutura dos serviços de saúde pode limitar tal abordagem. Por outro lado, sabe-se que valores fixos de reposição volêmica freqüentemente subestimam a real necessidade de fluidos do paciente séptico. Adicionalmente, a síndrome séptica do dengue, à semelhança da sepse de outras etiologias, pode também cursar com Síndrome da Angústia Respiratória do Adulto (SARA), tendo a reposição volêmica excessiva um papel prejudicial nesses casos, ainda que esse risco não justifique a inadequação da oferta hídrica ao paciente séptico.

O guia terapêutico do dengue publicado pela OMS e outros manuais não enfatizam o uso de drogas vasoativas, o que seria desejável nos casos refratários à reposição volêmica e que evoluem com instabilidade hemodinâmica. Assim, aminas vasoativas como dopamina e noradrenalina podem auxiliar na manutenção de níveis pressóricos arteriais médios em torno de $60-70 \mathrm{mmHg}$, os quais garantem a perfusão adequada dos sistemas orgânicos. Além disso, como vimos anteriormente, esses pacientes podem apresentar depressão cardíaca significativa, momento em que podem se beneficiar da infusão de um medicamento inotrópico, como a dobutamina. Tais aspectos nos parecem relevantes na prevenção da chamada síndrome de falência orgânica múltipla, cenário final de praticamente todo paciente séptico que evolui para a morte ${ }^{24}$.

Na sepse de qualquer etiologia, os níveis adequados de hemoglobina a serem mantidos são discutíveis, embora trabalhos recentes indiquem que não há vantagem em mantê-los acima de $9 \mathrm{~g} \%{ }^{13}$ a despeito da constatação de que há quebra dos mecanismos compensatórios da anemia nesses pacientes (aumento da deformabilidade das hemácias, desvio da curva de dissociação da oxihemoglobina, aumento do 2,3-DPG e redistribuição do fluxo sanguíneo).

A oxigenação adequada deve ser implementada em todos os pacientes e freqüentemente há necessidade de assistência ventilatória mecânica. Não se deve protelar tal assistência, uma vez que o esforço respiratório desses pacientes eleva a carga de trabalho da respiração de $4-7 \%$ para até $60 \%$ do gasto energético corporal, desviando sangue de órgãos nobres como o cérebro, rins e coração. Assim, sobretudo nos pacientes com bicarbonato sérico menor que 16 e com baixa reserva orgânica, a ventilação mecânica deve ser considerada. Quando se desenvolve SARA, há grave alteração das trocas gasosas, com aumento na dificuldade de oxigenação, mesmo sob ventilação mecânica, ocorrendo piora significativa do prognóstico. Nas fases iniciais da SARA deve-se atentar para o excesso de infusão hídrica, mas não deixando por isso de se fazer reposição volêmica adequada.

Se, depois de instituídas as medidas acima, não ocorrer diurese adequada (pelo menos $0,5 \mathrm{ml} / \mathrm{kg} / \mathrm{h}$ ), deve-se administrar diuréticos de alça, oferecendo-se elevadas doses se necessário (furosemida até $1 \mathrm{mg} / \mathrm{kg} / \mathrm{hora}$ ). A associação de dopamina em baixas doses parece ser benéfica nesses casos, ainda que sem comprovação científica. Métodos dialíticos podem ser empregados para correção de sobrecarga hídrica, hipercalemia, uremia ou acidemia grave. A alcalinização da urina se mostra justificada nos pacientes com icterícia importante. A icterícia muito raramente ocorre no dengue.

Para os pacientes que evoluem com quadros mais arrastados, o apoio nutricional adequado deve ser instituído o mais precocemente possível. Esse é feito preferencialmente por via enteral ${ }^{34} 35$. Embora no dengue espera-se que isso não seja necessário, pois a evolução do paciente para a recuperação ou o óbito é rápida, os casos graves 
que receberem tratamento adequado terão evolução mais arrastada devido à maior gravidade da doença e às complicações esperadas nessas situações, tais como SARA, MODS e infecções secundárias.

Os pacientes que apresentam distúrbios da coagulação sangüínea com manifestações hemorrágicas devem ser avaliados quanto às repercussões hemodinâmicas e receber reposição volêmica de cristalóides, sangue e/ou hemoderivados de acordo com a Tabela 3. As classes 1 e 2 encontram indicação de receber reposição de cristalóides enquanto as classes 3 e 4 devem receber sangue e hemoderivados (Tabela 3).

Tabela 3 - Classificação da hemorragia baseada na extensão da perda sangüínea.

\begin{tabular}{|c|c|c|c|c|}
\hline \multirow[b]{2}{*}{ Parâmetros } & \multicolumn{4}{|c|}{ Classificação da Hemorragia } \\
\hline & classe 1 & classe 2 & classe 3 & classe 4 \\
\hline Perda sanguínea & $<15 \%$ & 15 a $30 \%$ & 30 a $40 \%$ & $>40 \%$ \\
\hline Frequência Cardíaca & $<100$ & $>100$ & $>120$ & $>140$ \\
\hline Pressão arterial & normal & normal & diminuída & diminuída \\
\hline Diurese (ml/hora) & $>30$ & 20 a 30 & 5 a 15 & $<5$ \\
\hline Estado mental & ansioso & agitado & confuso & letárgico \\
\hline
\end{tabular}

A utilização de terapias alternativas, direcionadas às citocinas e toxinas envolvidas na sepse, tem sido estudada e incluem o uso de anticorpos policlonais, monoclonais e fração Fab de anticorpos. Eles podem ser dirigidos contra o FNT-alfa, IL-1, IL-6 e outros. Pode-se citar também os inibidores da ciclooxigenase como aspirina, corticóide e ibuprofeno. O corticóide teve seu uso definitivamente desaconselhado após estudos publicados em $1987^{232}$. Também no dengue não tem se mostrado eficaz ${ }^{27}$. Inibidores do fator ativador de plaquetas (PAF), pentoxifilina, antioxidantes, n-acetilcisteína, além de inibidores das endorfinas naturais como o naloxone e de antagonistas da bradicinina, também têm sido tentados ${ }^{7}$. Alguns trabalhos têm sugerido que 0 uso de inibidores do óxido nítrico pode ser benéfico, sobretudo nos casos de hipotensão refratária. $\mathrm{O}$ uso de infusão contínua de azul de metileno, por exemplo, mostra-se benéfico, com toxicidade mínima ${ }^{521}$. Infelizmente, até o momento, nenhum dos agentes citados revelou benefícios consistentes na sobrevida de pacientes com sepse.

Considerações finais. Sabemos que o dengue não se resolve com o tratamento dos doentes. Todavia enquanto não se adotam medidas eficientes para o seu controle e erradicação, resta-nos investir racionalmente na terapêutica, na educação médica e na divulgação de informações necessárias para que os pacientes cheguem aos serviços de saúde nas fases iniciais da doença e assim possam ser atendidos e referenciados de acordo com o nível de atenção médica requerida para cada caso ${ }^{28}$.

Uma vez atendidos e/ou referenciados ao local indicado, o tratamento se processará automaticamente, pois a classificação do dengue proposta no fluxograma acima incorpora os conceitos atuais de sepse, SIRS e SARA, serve como guia para orientar a conduta inicial e aproximar a terapêutica do dengue aos protocolos e às rotinas já implantadas nos centros hospitalares, proporcionando, com isso, maior agilidade e melhores resultados, e facilitando a atuação dos serviços de saúde em situações de surtos epidêmicos.

Estudos tornam-se necessários para melhor entendimento dos mecanismos fisiopatológicos do dengue, especialmente os que evoluem com choque (conseqüente a hemorragias, a sepse ou a ambas). O diagnóstico diferencial abrange doenças bacterianas e virais, tais como: sepse bacteriana, leptospiroses, ricketsioses, hantavírus, febre amarela, outras arboviroses e febres hemorrágicas. Considerando que na vigência de surto epidêmico de dengue seu diagnóstico poderá ser supervalorizado, enquanto não se estabelece o diagnóstico específico, o tratamento, mesmo que síndrômico, propiciará melhor prognóstico, inclusive para as outras doenças.

O raciocínio proposto para o dengue no presente estudo talvez possa ser aplicado a outras doenças infecciosas e febres hemorrágicas que cursam com sepse. 


\section{REFERÊNCIAS BIBLIOGRÁFICAS}

1. American College of Chest Phisycians/Society of Critical Care Medicine Consensus Conference for the: Committe ACCP/SCCM Consensus Conference. Definitions for sepsis and organ failure and guidelines use of innovative therapies in sepsis. Critical Care Medicine 20:864-874, 1992.

2. Bone RC, Fisher CJ, Clemmer TP, Slotman GJ, Metz CA, Balk RA. A controlled clinical trial of high-dose methylprednisolone in the treatment of severe sepsis and septic shock. New England Journal of Medicine 317:653658, 1987.

3. Bone RC, Fisher Jr CJ, Clemmer TP, Slotman GJ, Metz CA, Balk RA. Sepsis syndrome: a valid clinical entity. Methylprednisolone Severe Sepsis Study Group. Critical Care Medicine 17:389-393, 1989.

4. Bone RC, Grodzin CJ, Balk RA. Sepsis: a new hypothesis for pathogenesis of the disease process. Chest 112:235243, 1997.

5. Brown G, Franke D, Phang T. Continuous infusion of methylene blue for septic shock. Postgraduate Medicine Journal 72:612-614, 1996.

6. Choi PT, Yip G, Quinonez LG, CooK DJ. Crystalloids vs. colloids in fluid resuscitation: a systematic review. Critical Care Medicine 27:200-210, 1999.

7. Christman JN, Holden EP, Blackwell TS. Strategies for blocking the systemic effects of cytokines in the sepsis syndrome. Critical Care Medicine 23:955-963, 1995.

8. Cochrane Injuries Group Albumin Reviewers. Cochrane Injuries Group, Department of Epidemiology and Public Health, Institute of Child Health, London WCIN IEH. British Medical Journal 317:235-240, 1998.

9. Cope JT, Banks D, Mauney MC, Lucktong T, Shockey KS, Kron IL, Tribble CG. Intraoperative hetastarch infusion impairs hemostasis after cardiac operations. Annals of Thoracic Surgery 63:78-82, 1997.

10. Dinarello CA. Cytokines as mediators in pathogenesis of septic shock. Current Topics in Microbiology and Immunology 216:133-165, 1996.

11. Esen F, Telci L, Cakar N, Tutuncu A, Keseciuglu J, Akpir $\mathrm{K}$. Comparison of gastric intramucosal $\mathrm{pH}$ measurements with oxygen supply, oxygen consumption and arterial lactate in patients with severe sepsis. Advances in Experimental Medicine and Biology 388:521-531, 1996.

12. Groeneveld $\mathrm{PH}$, Kwappenberg KM, Langermans JA, Nibbering $\mathrm{PH}$, Curtis L. Nitric Oxide (NO) production correlates with renal insufficiency and multiple organ dysfunction syndrome in severe sepsis. Intensive Care Medicine 22:1197-1202, 1996.

13. Hebert PC, Wells G, Blajchman MA, Marshall J, Martin C, Pagliarello G, Tweeddale M, Schweitzer I, Yetisir E. A multicenter, randomised, controlled clinical trial of transfusion requirements in critical care. Tranfusion Requirements in Critical Care Investigators for the Canadian Critical Care Trials Group. New England Journal of Medicine 340:409-417, 1999.

14. Irwin RS, Cerra FB, Rippe JM. Intensive Care Medicine. $4^{\text {th }}$ edition. New york: Lippincott-Raven. Cap. 184a, b e c: Sepsis and other shock states: derangements of oxigen trasport; Sepsis; Multiple organ dysfunction syndrome, p. 2023-2047, 1999.

15. Kapra SK, Juneja R, Madhuli KA. Myocardial dysfunction in children with dengue haemorrhagic fever. National Medical Journal of India 11:59-61, 1988.

16. Levi M, Ten Cate H. Disseminated intravascular coagulation. New England Journal of Medicine 341:586592, 1999.

17. Mardel SN, Saunders FM, Allen H, Menezes G, Edwards CM, Ollerenshaw L, Baddeley D, Kennedy A, Ibbotson RM. Reduced quality of clot formation with gelatin-based plasma substitutes. British Journal of Anesthesiology 80:204-207, 1998.

18. Parker MM, Shelhamer JH, Bacharach SL, Green MV, Natanson C, Frederik TM, Damske BA, Parrillo JE. Profound but reversible myocardial depression in patients with septic shock. Annals of Internal Medicine 10:483490, 1984.

19. Parrillo JE. Pathogenetic mechanisms of septic shock. New England Journal of Medicine 20:1471-1477, 1993.

20. Parsons PE, Moss M. Early detection and markers of sepsis. Chest 17:199-212, 1996.

21. Preiser JC, Lejeune P, Roman A, Carlier E, Backer D, Luman M, Kahn RJ. Methylene blue administration in septic shock: a clinical trial. Critical Care Medicine 23:259294, 1995.

22. Pulmonary Artery Catheter Consensus Conference. Critical Care Medicine 25:910-925, 1997.

23. Rigau-Peréz JG, Clark GG, Gubler DJ, Reiter P, Sanders EJ, Vorndam AV. Dengue and dengue haemorrhagic fever. Lancet 352:971-977, 1998.

24. Rudis MI, Basha MA, Zarowitz BJ. Is it time to reposition vasopressors and inotrops in sepsis? Critical Care Medicine 24:525-537, 1996.

25. Schierhout G, Roberts I. Fluid resuscitation with colloid or crystalloid solutions in critically ill patientes: a systematic review of randomised trials. British Medical Journal 316:961-964, 1998.

26. Serufo JC, Souza AM, Tavares VA, Jammal MC, Silva JG. Dengue in the South-eastern region of Brazil: historical analysis and epidemiology. Revista de Saúde Pública 27:157-167, 1993.

27. Skandan S, Cohen J. The pathogenesis of septic shock. Journal of Infectology 30:201-206, 1995. 
28. Tassnisson S. Failure of high-dose methylprednisolone in established dengue shock syndrome: a placebocontrolled, double-blind study. Pediatrics; 92:111-115, 1993.

29. Thigs LG, de Boer JP, de Groot MC, Halk CE. Coagulation disorders in septic shock. Intensive Care Medicine 19:S8S15, 1996.

30. Thong MK. Dengue shock syndrome and acute respiratory distress syndrome. Lancet 352:1712, 1998.

31. Trumble ER, Muizelaar JP, Myseros JS. Coagulopathy with the use of hetastarch in the treatment of vasoespasm. Journal of Neurosurgery 82:44-47, 1995.

32. The Veterans Administration Sepsis Cooperative Study Group. Effects of high-dose glucocorticoid threrapy on mortality in patients with clinical signs of systemic sepsis. New England Journal of Medicine 317:659-665, 1987.

33. Vicent JL. Dear SIRS, I'm sorry to say that I don't like you.... Critical Care Medicine 25:372-374, 1997.

34. Warren HS. Strategies for the treatment of sepsis. New England Journal of Medicine 17:952-953, 1997.

35. Wheeler AP, Bernard GR. Treating patients with severe sepsis. New England Journal of Medicine 340:207-214, 1999.

36. Wiles JB, Cerra FB, Siegel JH, Border JR. The systemic septic response: does the organism matter? Critical Care Medicine 8:55-60,1980.

37. World Health Organization. Dengue haemorrhagic fever: diagnosis, treatment, prevention and control. $2^{\text {nd }}$ edition. WHO, Genebra, p.1-83, 1997. 